\title{
AlloDerm implants for prevention of Frey syndrome after parotidectomy: A systematic review and meta-analysis
}

\author{
XIAN-TAO ZENG ${ }^{1}$, XIANG-JUN TANG ${ }^{2}$, XUE-JUN WANG ${ }^{3}$, MIAO-ZHU LI $^{4}$, \\ YI GUO $^{5}$, WEI HUANG ${ }^{1}$, YU-MING NIU ${ }^{1}$ and WEI-DONG LENG ${ }^{1}$ \\ Departments of ${ }^{1}$ Stomatology, ${ }^{2}$ Neurosurgery, and ${ }^{3}$ Emergency Surgery, Taihe Hospital, Hubei University of Medicine, \\ Shiyan, Hubei 442000; ${ }^{4}$ Institute for Nutritional Sciences, Shanghai Institute for Biological Sciences, \\ Chinese Academy of Sciences, Shanghai; ${ }^{5}$ Department of Epidemiology, School of Public Health, \\ Wuhan University, Wuhan, Hubei 430071, P.R. China
}

Received December 1, 2011; Accepted January 18, 2012

DOI: $10.3892 / \mathrm{mmr} .2012 .762$

\begin{abstract}
Although Frey syndrome is not life-threatening, it is identified as the most serious and widely recognized sequela of parotidectomy and has significant potential negative social and psychological implications. Several studies have investigated whether AlloDerm ${ }^{\circledR}$ implants prevent Frey syndrome effectively and safely, however, the conclusions are inconsistent. We aimed to evaluate the precise effectiveness of AlloDerm implants for preventing Frey syndrome after parotidectomy, using a systematic review and meta-analysis. We searched randomized and quis-randomized controlled trials in which AlloDerm implants were compared to blank controls for preventing Frey syndrome after parotidectomy, from the PubMed, Embase, the Cochrane Library and the ISI Web of Knowledge databases, without any language restriction. Two reviewers independently searched, identified, extracted data and assessed methodological quality. Relative risks with 95\% confidence intervals were calculated and pooled. Five articles involving 409 patients met the inclusion criteria. Metaanalyses showed a significant $85 \%$ relative risk reduction in objective incidence $(\mathrm{RR}=0.15,95 \%$ CI 0.08-0.30; $\mathrm{P}<0.00001)$ and $68 \%$ in subjective incidence $(\mathrm{RR}=0.32,95 \% \mathrm{CI} 0.19-0.57$; $\mathrm{P}<0.00001)$ of Frey syndrome with AlloDerm implants; there was a significant $91 \%$ relative risk reduction in salivary fistula ( $\mathrm{RR}=0.09,95 \%$ CI $0.01-0.66 ; \mathrm{P}=0.02)$; there was no statistical significance for the incidence of facial nerve paralysis ( $\mathrm{RR}=0.96,95 \%$ CI $0.84-1.09 ; \mathrm{P}=0.51$ ); there was no statistical significance for the incidence of seroma/sialocele $(\mathrm{R} R=1.36$, 95\% CI 0.66-2.80; $\mathrm{P}=0.40)$; there was a trend for a small effect in improving facial contour. Adverse events related to AlloDerm implants were not found. There is evidence that
\end{abstract}

Correspondence to: Dr Wei-Dong Leng, Department of Stomatology, Taihe Hospital, Hubei University of Medicine, 32 South Renmin Road, Shiyan, Hubei 442000, P.R. China

E-mail: zengxiantao1128@163.com

Key words: AlloDerm, Frey syndrome, parotidectomy, saliva fistula, systematic review, meta-analyses
AlloDerm reduces the incidence of Frey syndrome effectively and safely, and also has the potential to improve facial contour and decrease salivary fistula. However, it is unclear whether AlloDerm implants improve facial contour and decrease other complications. Thus, further controlled evaluative studies incorporating more precise measures are required.

\section{Introduction}

Neoplasms of the salivary glands constitute 3-10\% of all tumors of the head and neck (1), and are located in the parotid gland in $34-86 \%$ of cases $(2,3)$. Among parotid tumors, benign tumors are more common than malignant ones $(4,5)$. Parotidectomy is commonly used in the treatment of gland tumors; it is the first choice to treat gland tumors (5-7). However, complications, such as Frey syndrome (8), transient or permanent facial nerve paresis (9), cosmetic disfigurement (10), pain and discomfort, and subsequent xerostomia, can reduce the quality of life of patients after parotidectomy (11). Among these complications, Frey syndrome has the highest incidence, from 11 to $95 \%$ (12-14).

Frey syndrome was first described by Łucja (Lucie) Frey in $1923(15,16)$. Andre Thomas in 1927 and later Ford and Woodhall in 1938 postulated the theory of aberrant regeneration of the sectioned parasympathetic fibers that regrow to innervate the vessels and sweat glands of the skin overlying the parotid to explain the symptoms $(15,17)$. Although Frey syndrome is not life-threatening, the surveys show that Frey syndrome and concave facial deformity are identified as the most serious self-perceived sequelae with significant potential negative social and psychological implications, which result in discomfort worsening with time $(7,11,12,18,19)$. Thus, the goals of parotidectomy are to remove the primary tumor, prevent severe functional loss, avoid cosmetic defects, and particularly to prevent Frey syndrome.

The therapeutic and preventive methods for Frey syndrome can be subdivided into surgical and non-surgical modalities. Non-surgical techniques used to prevent Frey syndrome include drugs; the most common is a local injection of botulinum toxin. Yet, this has many side effects, including mild and temporary muscle weakness and pain at the injection site, 
easy recrudescence, and the procedure also frequently affects the quantity and quality of salivary flow $(20,21)$.

The major surgical techniques include implantation of a 'barrier', including autogenous vascularized tissue [such as the sternocleidomastoid muscle flap (22), temporoparietal fascia rotational flap (23) and the superficial muscular aponeurotic system (24)], non-vascularized tissue [such as fascia lata (25) and dermis fat grafts (26)], and synthetic biomaterials [such as expanded polytef (27)]. However, these surgical management options are limited by at least one of the following factors: i) the need for a second operation (with its associated potential morbidity), ii) the need for an additional donor site, iii) prolonged period of time under general anesthesia, iv) insufficient amount of tissue to cover the wound surface completely, v) inability to reduce the incidence of Frey syndrome (28), and vi) the higher incidence of wound infection, rejection reaction or other postoperative complications (29).

A 'barrier' that is able to demonstrate efficacy with regard to preventing Frey syndrome, while at the same time eliminating the disadvantages mentioned above would be prefered and is now being considered. AlloDerm ${ }^{\circledR}$, in addition to serving as a nerve barrier, may serve as an effective soft tissue augmentation device in the head and neck region $(30,31)$. Since it undergoes fibrous tissue ingrowth, has extensive sources, convenient manufacturing, efficient industrialization and virtually no side effects, it is considered as an ideal barrier in the field of oral health to date (32).

The first published study on the utilization of AlloDerm in humans was conducted by MacKinnon in 1997 (33), and it has been widely used in this field and reported in many research articles (34-41). It is a new type of biological material, yet its long-term side effects are unknown. Therefore, we performed this systematic review and meta-analysis in order to evaluate the effectiveness and safety of AlloDerm to prevent Frey syndrome after parotidectomy.

\section{Materials and methods}

Selection of studies. A comprehensive systematic search was conducted by two independent reviewers (X.T.Z. and M.Z.L.) in PubMed (1966 to May 2011), Embase (1974 to May 2011), the Cochrane Library (issue 4, 2011) and the ISI Web of Knowledge databases (1994 to May 2011) for relevant citations. In addition, we searched the reference lists of all known primary and review articles. All identified articles were screened for cross-references; no language restrictions were imposed.

The search terms were combined with ('Frey syndrome' OR 'Frey's syndrome' OR 'gustatory sweating' OR 'auriculotemporal syndrome') AND ('AlloDerm' OR 'acellular tissue patch' OR 'acellular dermal matrix' OR 'acellular dermal' OR 'acellular dermis' OR 'Permacol' OR 'porcine dermal matrix' OR 'allograft dermis' OR 'allograft dermal matrix'), then duplicated results were removed. The remaining citations were displayed and examined.

Inclusion and exclusion criteria. Eligibility was determined by two independent reviewers (X.J.T. and W.H.), with consensus from the third reviewer (W.D.L.), on the basis of information found in the article's title, abstract or full text.
Studies were included in the review if they met the following criteria: randomized controlled trials (RCTs) and quasi-RCTs of all the articles, the study patients included adults ( $\geq 18$ years) who were diagnosed with parotid tumors and had received a partial or total parotidectomy with facial nerve preservation, AlloDerm was applied as the experimental group and a placebo (blank) as the control group. Studies that included patients with previous surgical procedures in the parotid area or with previous radiotherapy were excluded. Review ariticles, commentaries, guidelines and letters were also excluded.

Data extraction. The data were extracted by two reviewers (X.J.W and Y.M.N.) independently. In case of discrepancies, a third reviewer (W.D.L.) was consulted and, after agreement, a consensus was reached. Data were extracted on publication data (the first author's last name, year of publication and country of population studied), sample size, patient characteristics (mean age and sex ratio), study design, follow-up period, outcome measures and method of measurement. Authors were contacted by e-mail for additional information if data was unavailable.

The primary outcome measure was the incidence of Frey syndrome (objective or subjective). Secondary outcomes included facial contour, adverse events (wound infection and rejection), other postoperative complications (seroma or sialocele, salivary fistula and facial nerve paralysis) that were noted when they were reported in the studies.

Quality assessment. We assessed the study quality using the Cochrane Handbook's evalution tool for assessing the risk of bias (42) and the Jadad scoring system (43). It was also conducted by two independent reviewers (X.T.Z. and M.Z.L.) and an agreement was reached after consulting a third reviewer (Y.G.).

The Cochrane Handbook's evalution tool included: Sequence generation - Was the allocation sequence adequately generated? Allocation concealment - Was allocation adequately concealed? Blinding - Was knowledge of the allocated intervention adequately blinded during the study? Blinding of participants and personnel? Blinding of outcome assessors? Incomplete outcome data - Were incomplete outcome data adequately addressed? Selective outcome reporting - Were reports of the study free of suggestion of selective outcome reporting? Other sources of bias - Was the study apparently free of other problems that could put it at a high risk of bias?

The Jadad scoring system included: Was the study described as randomized? Was the method used to generate the sequence of randomization described and appropriate? Was the study described as double-blind? Was the method of double-blinding described and appropriate? Was there a description of withdrawals and dropouts?

This is a five-point scale, with low-quality studies having a score of $\leq 2$ and high-quality studies a score of at least 3 .

Statistical analysis. Data were processed in accordance with the Cochrane Handbook (42). Intervention effects were expressed with relative risks (RRs) and associated 95\% confidence intervals (CIs) for dichotomous data and mean differences (MDs) and 95\% CIs for continuous data, respec- 


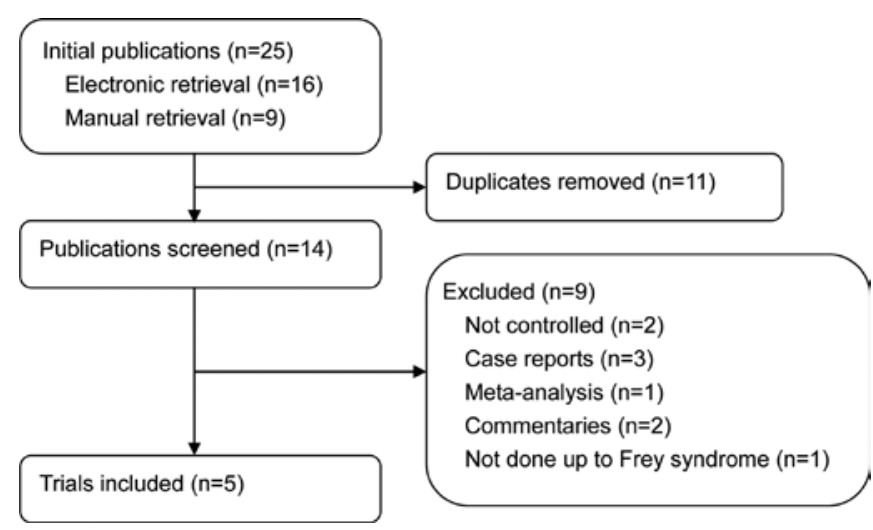

Figure 1. Summary of the study selection process.

tively. Heterogeneity among studies was informally assessed by visual inspection of forest plots, and formally estimated using the Chi-square test and $\mathrm{I}^{2}$ test (both $\mathrm{P}>0.05$ and $\mathrm{I}^{2}<50 \%$ indicated there was no evidence of heterogeneity between the pooled studies) (44). The fixed-effects model was first used for meta-analyses; if there was heterogeneity, the randomeffects model was used. Publication bias was tested from separate funnel plots (when the number of included studies was $\geq 9$ ). Symmetry of and outlying results on, the funnel plots implied lack of bias, whereas asymmetry would imply that the results were subject to reporting or publication bias (45). All statistical analyses were performed using Review Manager (version 5.0.2; The Cochrane Collaboration). Description analysis was performed when the quantitative data could not be pooled. The data were entered into Review Manager by X.T.Z., and M.N.Y. checked data entry.

\section{Results}

Characteristics and quality of the included studies. A database search yielded 25 publications, of which both of the reviewers considered 14 to be potentially eligible. We excluded 9 of the articles during the second phase of the inclusion process, 2 were not controlled $(39,41), 3$ were case reports $(33,40,46)$ and 1 was a meta-analysis $(47)$. One was not done up to Frey syndrome (48) and 2 were commentaries $(49,50)$. The remaining 5 articles were included in the metaanalysis (34-38). A summary of the study selection process is presented in Fig. 1. There were 3 studies published in English $(34,36,37)$ and 2 in Chinese $(35,38)$. A total of 409 participants were included. The sample size ranged from 20 to 168 , and the follow-up period ranged from 5 to 39 months. All of the studies had similar eligibility criteria (Table I).

There was good agreement between the reviewers in regards to the validity assessments. All studies were clinical controlled trials, and the methodological quality of the included trials ranged from poor to excellent (Table I). Fig. 2 shows the risk of bias summary; the majority had adequate patient followup, and the main study biases may be caused by sample size, randomization, the procedure for concealing the treatment allocation and blinding (as it is not feasible to blind staff in these studies, blinding of investigators is feasible). For example, only 1 study (35) mentioned randomization and blinding, but did not describe how the random allocation sequence was generated.

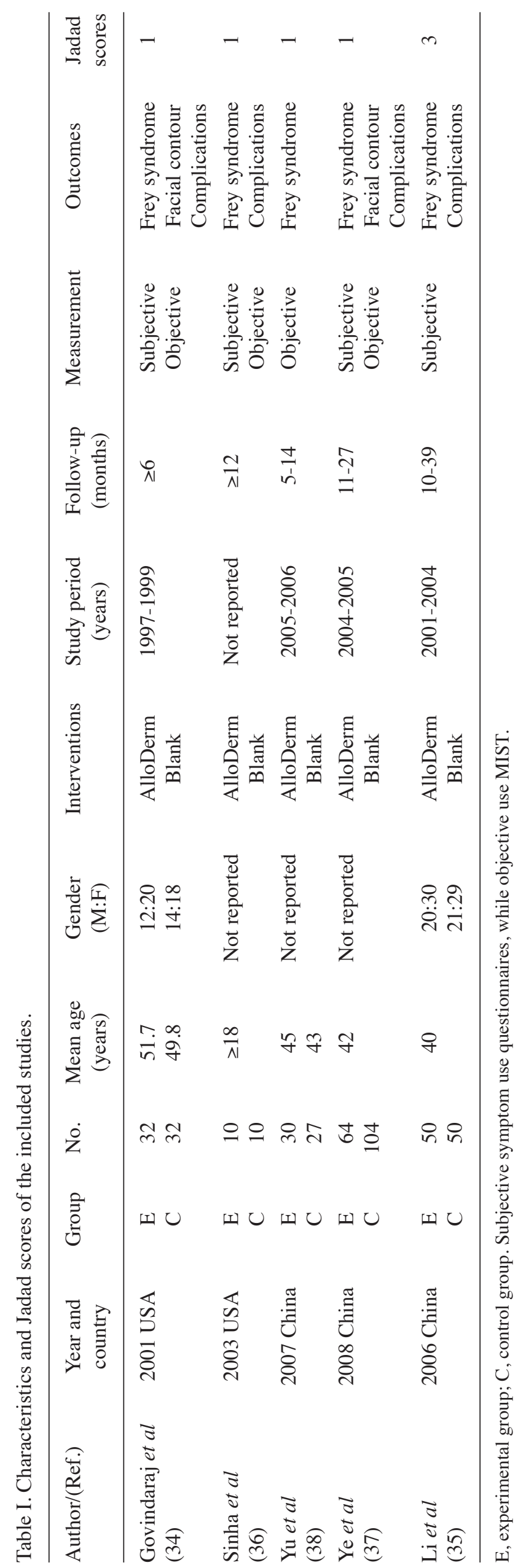




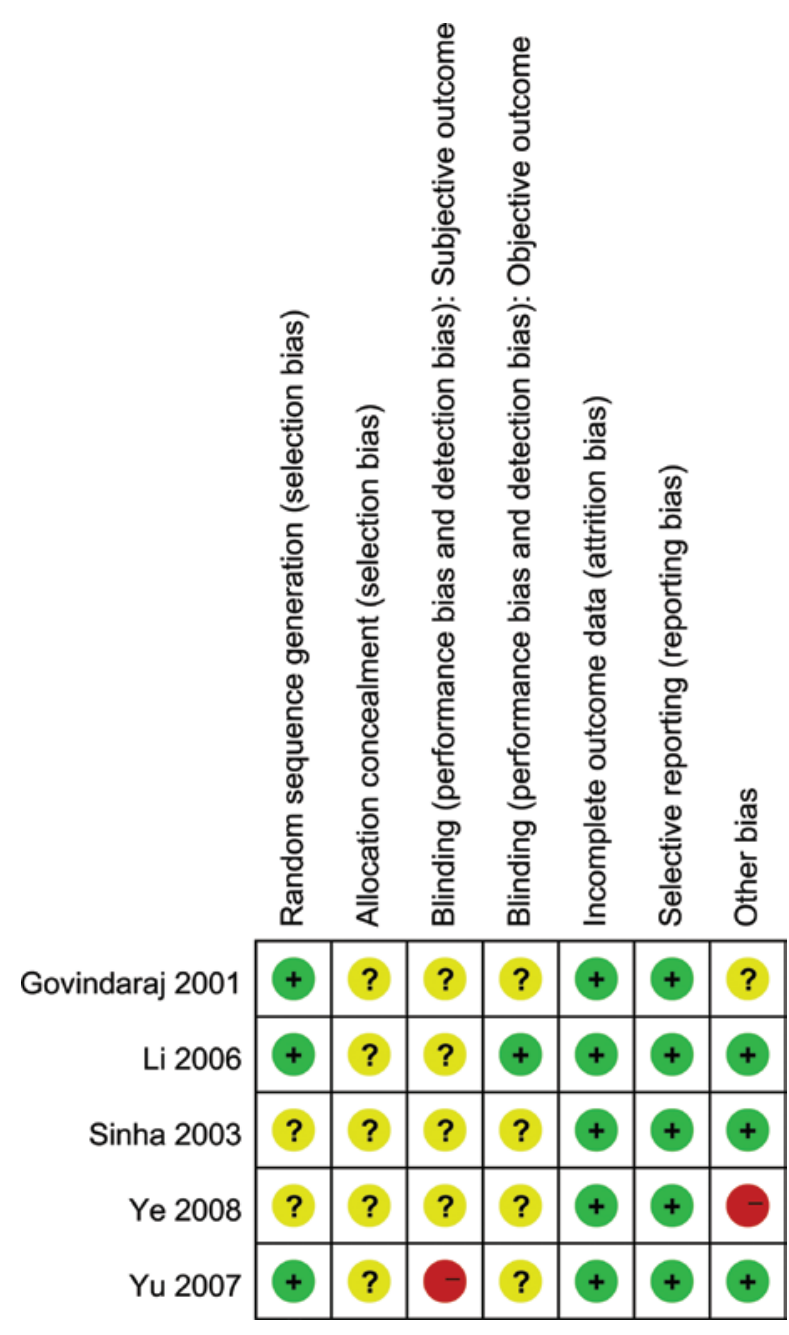

Figure 2. Summary risk of bias assessment.

Frey syndrome. We extracted data for the incidence of Frey syndrome from the included 5 studies. Four studies reported data of the objective incidence (34,36-38), for which outcomes were consistent across studies (heterogeneity $\mathrm{P}=0.49, \mathrm{I}^{2}=0 \%$ ), so the fixed effects model was used. The result showed that there was a significant trend toward lower incidence in the AlloDerm group (Fig. 3; RR=0.15, 95\% CI 0.08-0.30; $\mathrm{P}<0.00001)$.

Four studies reported data involving subjective incidence (34-37); there was significant heterogeneity $\left(\mathrm{P}=0.01, \mathrm{I}^{2}=71 \%\right)$, therefore, the random effects model was used. The result also showed that there was a significant trend toward lower incidence in the AlloDerm group ( $\mathrm{R} R=0.16$, 95\% CI 0.09-0.28; $\mathrm{P}<0.00001)$. We explored possible causes of heterogeneity, taking into account the imbalance of patients between the two groups in one trial (37). When we excluded this trial from the analysis, the heterogeneity disappeared (Fig. 4; $\mathrm{P}=0.83$, $\mathrm{I}^{2}=0 \%$, and the trend toward the AlloDerm group weakened (Fig. 4; RR=0.32, 95\% CI 0.19-0.57; P<0.00001).

Facial contour. Two trials reported the perception of cosmetic appearance and facial symmetry $(36,37)$. They found that using AlloDerm to fill in the parotid bed resulted in better cosmesis and restoration of good soft tissue contour at the surgical site (symmetrical, with fine scars), while the scars of the control patients were noticeable, locally depressed and with wrinkled skin.

Adverse events. Adverse events in the original studies consisted of wound infection and rejection. Four studies reported data on wound infection (34-37); there was no significant trend toward increased incidence in the AlloDerm group (Fig. 5; RR=3.00, 95\% CI 0.14-65.90; $\mathrm{P}=0.49)$. The reason for the adverse event was streptococcus species, not the AlloDerm (36).

Four studies reported data for rejection (34-37), but all of them reported that there were no cases of implant extrusion that occurred in the AlloDerm group.

Other postoperative complications. Other postoperative complications in the original studies consisted of seroma/ sialocele, saliva fistula and facial nerve paralysis. Fig. 6 summarizes the results.

Three studies reported data regarding seroma/sialocele (34-36), for which outcomes were consistent across studies $\left(\mathrm{P}=0.46, \mathrm{I}^{2}=0 \%\right)$. There was no significant trend toward an increase in incidence in the AlloDerm group $(\mathrm{R} R=1.36,95 \%$ CI 0.66-2.80; $\mathrm{P}=0.40)$.

Two studies reported data regarding salivary fistula $(36,37)$, the result revealed that the incidence was lower in the AlloDerm group and the difference had statistical significance ( $\mathrm{RR}=0.09,95 \%$ CI 0.01-0.66; $\mathrm{P}=0.02$ ).

Three studies reported data concerning facial nerve paralysis (34-36); there was no significant trend toward a lower incidence in the AlloDerm group $(\mathrm{RR}=0.96,95 \% \mathrm{CI}$ 0.84-1.09; $\mathrm{P}=0.51$ ).

\section{Discussion}

Principal findings. Our systematic review identified 5 studies that addressed the relative impact of AlloDerm and a blank control. We found that the use of AlloDerm was associated with significant reductions in Frey syndrome (both subjective and objective symptoms) after parotidectomy.

The period of onset of Frey syndrome is more than 3-6 months after surgery: 3 years (51), 8 and a half years (52) and, at present, the longest is 14 years (53) as reported in research articles. The follow-up period ranged from 5 to 39 months in the included studies, so we believe that the preliminary results are reliable.

The present meta-analysis confirms that, despite various confounding factors, AlloDerm does decrease the occurrence of Frey syndrome after parotidectomy by $85 \%$ (objective) and $68 \%$ (subjective). We also found a possible trend that AlloDerm may decrease the incidences of salivary fistula and facial nerve paralysis, and improve facial contour. Although AlloDerm has several potential adverse effects, they are minimal compared to Frey syndrome and other complications, and these effects are able to be prevented or solved easily.

Strengths and limitations. Our study is more precise than previous ones (47). Previously published meta-analyses have focused on the preventive effect of surgical techniques, and carried out a search only in PubMed for English-language studies. They included many surgical techniques (AlloDerm was one of them), yet no subgroup analysis was performed, 


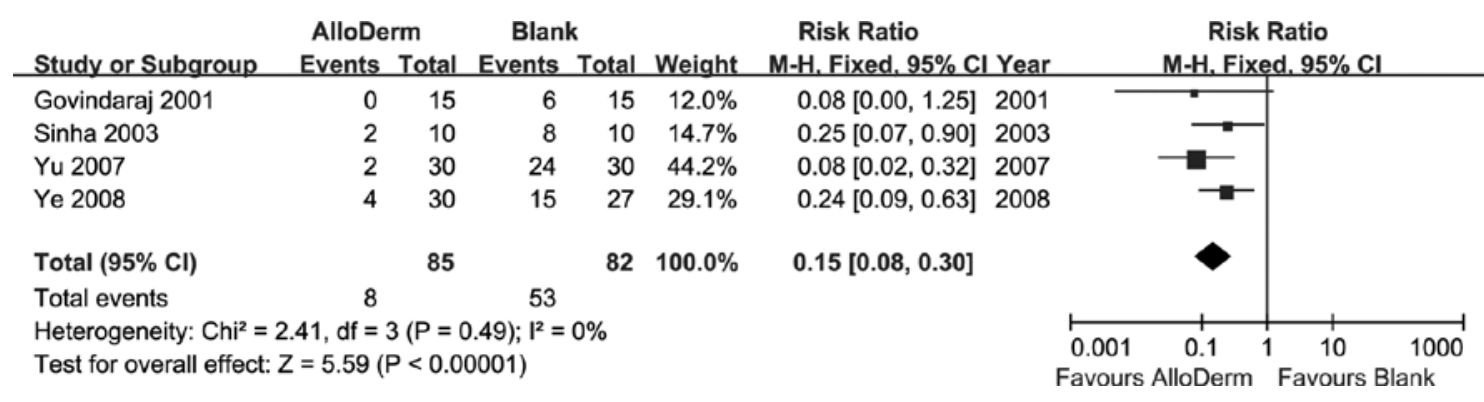

Figure 3. Effect of AlloDerm on the objective incidence of Frey syndrome.

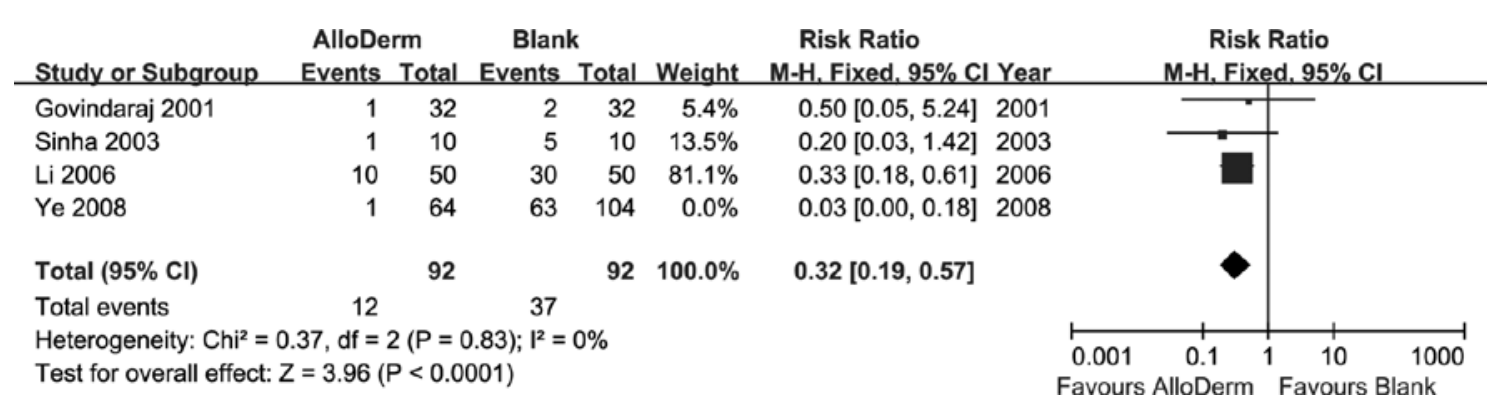

Figure 4. Effect of AlloDerm on the subjective incidence of Frey syndrome.

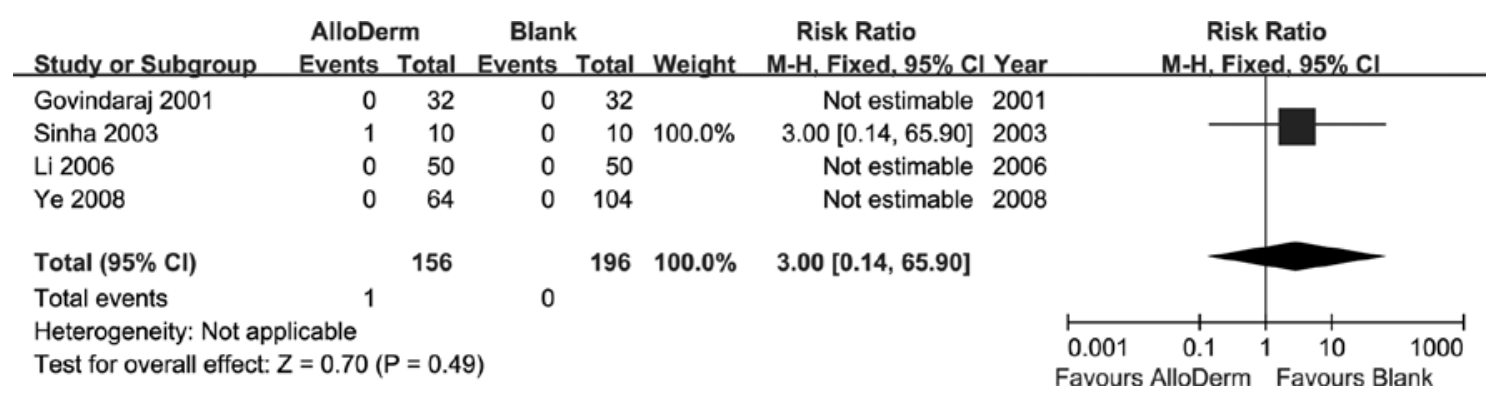

Figure 5. Effect of AlloDerm on the incidence of infection.

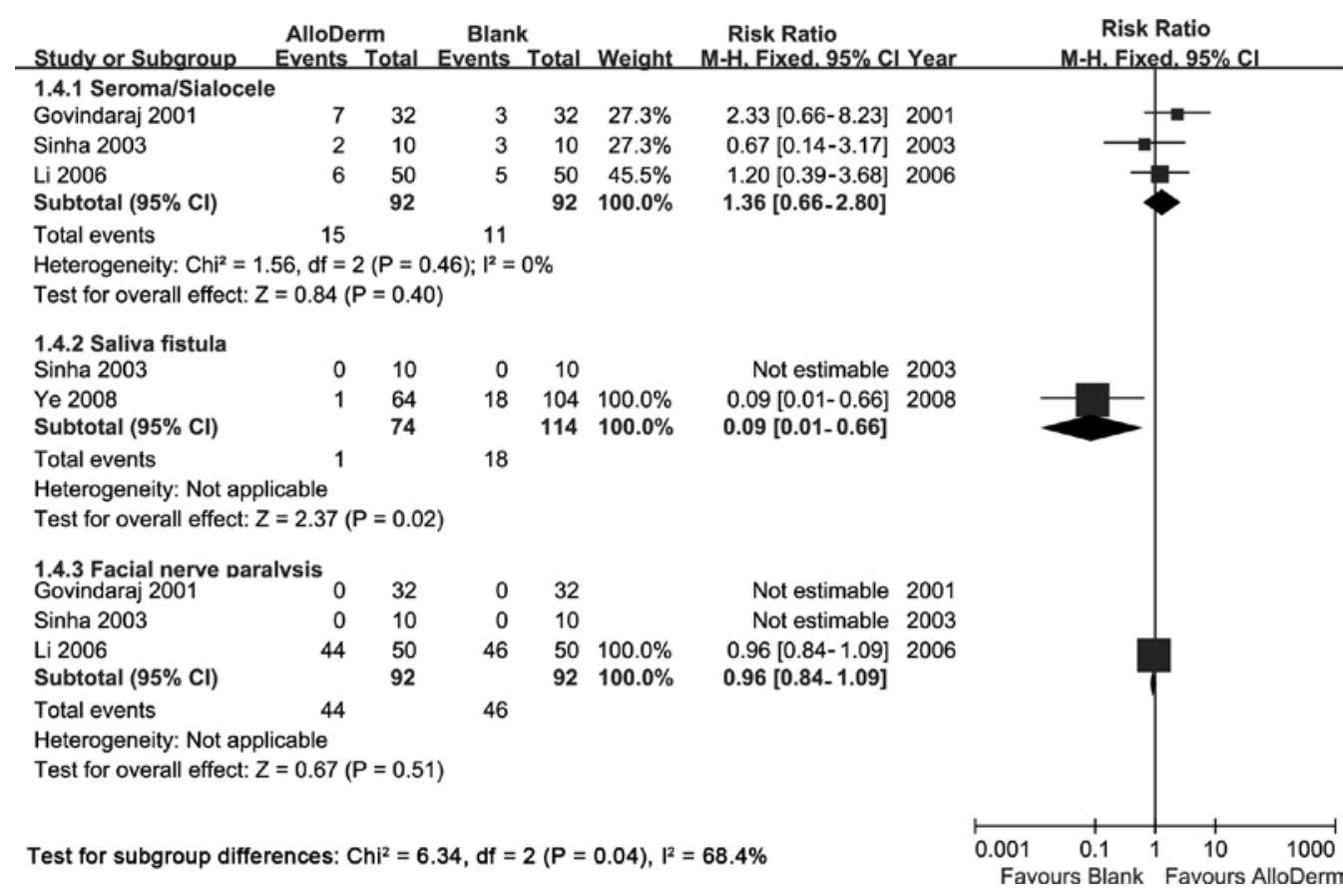

Figure 6. Effect of AlloDerm on other postoperative complications. 
although heterogeneity was high. Therefore, the authors suggested that further studies were necessary to stratify differences among the various available techniques. Also, they did not take into account adverse events or other complications.

Our study also has limitations. Firstly, the number of studies contributing substantial data to the meta-analysis was small; therefore, we could not fully assess the effects of important clinical factors that may have influenced outcomes. Possible problems with concealment, lack of blinding and loss of follow-up could have introduced bias. The sample sizes were quite few, thus we could not adequately assess effects. Finally, potential limitations of any meta-analysis is the 'file-drawer' effect, in which studies with negative results may remain unpublished, thus biasing the literature toward positive findings.

Clinical and policy implications. Our results may have potential implications for clinical practice and health policy. Frey syndrome is a widely recognized sequela of parotidectomy; there exist many strategies for both its prevention and treatment. Before the development of AlloDerm, previous strategies were able to effectively prevent Frey syndrome (47), but had various disadvantages $(20,21,28,29)$. Our results, although based on only 5 randomized controlled trials, indicate that it is plausible that AlloDerm delivers a clinically significant reduction in preventing Frey syndrome, without adverse effects. It may also reduce salivary fistula and facial nerve paralysis, and improve facial contour.

Shuman and Bradford (54) supported the fact that surgeons are obligated to inform patients regarding the significance of Frey syndrome prior to surgery. Yet, to date the process of informed consent and pre-operative decision-making has posed a potential ethical quandary. Many studies have also come to the conclusion that Frey syndrome interferes with the quality of life of patients $(7,11,12,18,19)$. Therefore, surgeons and policy makers need to address the clinical importance and value of the heighted focus in relation to the goals of treatment, so that AlloDerm may meet their and their patients' expectations.

Implications for research. The methods in trials were limited by the inability to blind clinical staff to the method of operation, yet the blinding of investigators to evaluate and collect outcome data is feasible. Unfortunately, only 1 study performed blinding of investigators (35). Therefore it is possible that the decisions and actions of the clinicians could have been influenced, resulting in biased estimates of treatment effect.

We also found that AlloDerm may reduce salivary fistula and facial nerve paralysis, and improve facial contour. As a result, future studies should follow the CONSORT 2010 statement (55) to design and report, in order to provide high-quality evidence.

In conclusion, evidence from the included studies suggests that use of AlloDerm results in decreased total incidence of Frey syndrome. Evidence also suggests that AlloDerm improves facial contour, may reduce salivary fistula and facial nerve paralysis, without adverse events. Yet limited data from the included studies is currently available to confirm this. Our study also shows that it is unclear whether the use of AlloDerm permits any conclusions about the incidence of other periop- erative complications. Further studies are required to establish the optimal design and optimal outcome indicators.

\section{Acknowledgements}

This study was supported by grants from the Foundation of Taihe Hospital of Shiyan City (2011QD01 and 2011QD05), without commercial or not-for-profit sectors.

\section{References}

1. Ansari MH: Salivary gland tumors in an Iranian population: a retrospective study of 130 cases. J Oral Maxillofac Surg 65: 2187-2194, 2007.

2. Vuhahula EA: Salivary gland tumors in Uganda: clinical pathological study. Afr Health Sci 4: 15-23, 2004.

3. Pinkston JA and Cole P: Incidence rates of salivary gland tumors: results from a population-based study. Otolaryngol Head Neck Surg 120: 834-840, 1999.

4. Li LJ, Li Y, Wen YM, Liu H and Zhao HW: Clinical analysis of salivary gland tumor cases in West China in the past 50 years. Oral Oncol 44: 187-192, 2008.

5. Smiddy FG: Treatment of mixed parotid tumours. Br Med J 1: 322-325, 1956.

6. Lim YC, Lee SY, Kim K, et al: Conservative parotidectomy for the treatment of parotid cancers. Oral Oncol 41: 1021-1027, 2005.

7. Clayman MA, Clayman SM and Seagle MB: A review of the surgical and medical treatment of Frey syndrome. Ann Plast Surg 57: 581-584, 2006.

8. Herxheimer A: Gustatory sweating and pilomotion. Br Med J 1: 688-689, 1958.

9. Patey DH: Risk of facial paralysis after parotidectomy. Br Med J 2: 1100-1102, 1963.

10. Mohyuddin N, Hoff SR and Yao M: The use of allograft dermis implants and the facelift incision in parotid surgery. Operative Techniques in Otolaryngology-Head and Neck Surgery 20: 114-119, 2009.

11. Nitzan D, Kronenberg J, Horowitz Z, et al: Quality of life following parotidectomy for malignant and benign disease. Plast Reconstr Surg 114: 1060-1067, 2004.

12. Koch M, Zenk J and Iro H: Long-term results of morbidity after parotid gland surgery in benign disease. Laryngoscope 120: 724-730, 2010

13. Harrison K and Donaldson I: Frey's syndrome. J R Soc Med 72: 503-508, 1979.

14. De Bree R, van der Waal I and Leemans CR: Management of Frey syndrome. Head Neck 29: 773-778, 2007.

15. Dulguerov P, Marchal F and Gysin C: Frey syndrome before Frey: the correct history. Laryngoscope 109: 1471-1473, 1999.

16. Dulguerov P, Marchal F and Gysin C: The bullet that hit a nerve: the history of Lucja Frey and her syndrome. J Laryngol Otol 120: $1087,2006$.

17. Glaister DH, Hearnshaw JR, Heffron PF, Peck AW and Patey DH: The mechanism of post-parotidectomy gustatory sweating (the auriculo-temporal syndrome). Br Med J 2: 942-946, 1958.

18. Baek CH, Chung MK, Jeong HS, et al: Questionnaire evaluation of sequelae over 5 years after parotidectomy for benign diseases. J Plast Reconstr Aesthet Surg 62: 633-638, 2009.

19. Beutner D, Wittekindt C, Dinh S, Huttenbrink KB and Guntinas-Lichius O: Impact of lateral parotidectomy for benign tumors on quality of life. Acta Otolaryngol 126: 1091-1095, 2006.

20. Bomeli SR, Desai SC, Johnson JT and Walvekar RR: Management of salivary flow in head and neck cancer patients - a systematic review. Oral Oncol 44: 1000-1008, 2008.

21. Wang CC and Wang CP: Preliminary experience with botulinum toxin type A intracutaneous injection for Frey's syndrome. J Chin Med Assoc 68: 463-467, 2005.

22. Asal K, Koybasioglu A, Inal E, et al: Sternocleidomastoid muscle flap reconstruction during parotidectomy to prevent Frey's syndrome and facial contour deformity. Ear Nose Throat J 84: $173-176,2005$.

23. Rubinstein RY, Rosen A and Leeman D: Frey syndrome: treatment with temporoparietal fascia flap interposition. Arch Otolaryngol Head Neck Surg 125: 808-811, 1999.

24. Moulton-Barrett R, Allison G and Rappaport I: Variation's in the use of SMAS (superficial musculoaponeurotic system) to prevent Frey's syndrome after parotidectomy. Int Surg 81: 174-176, 1996. 
25. Wallis KA and Gibson T: Gustatory sweating following parotidectomy: correction by a fascia lata graft. Br J Plast Surg 31: 68-71, 1978.

26. Chandarana S, Fung K, Franklin JH, Kotylak T, Matic DB and Yoo J: Effect of autologous platelet adhesives on dermal fat graft resorption following reconstruction of a superficial parotidectomy defect: a double-blinded prospective trial. Head Neck 31: 521-530, 2009.

27. Shemen LJ: Expanded polytef for reconstructing postparotidectomy defects and preventing Frey's syndrome. Arch Otolaryngol Head Neck Surg 121: 1307-1309, 1995.

28. Guntinas-Lichius O, Gabriel B and Klussmann JP: Risk of facial palsy and severe Frey's syndrome after conservative parotidectomy for benign disease: analysis of 610 operations. Acta Otolaryngol 126: 1104-1109, 2006

29. Dulguerov P, Quinodoz D, Cosendai G, Piletta P, Marchal F and Lehmann W: Prevention of Frey syndrome during parotidectomy. Arch Otolaryngol Head Neck Surg 125: 833-839, 1999.

30. Achauer BM, Van der Kam VM, Celikoz B and Jacobson DG: Augmentation of facial soft-tissue defects with Alloderm dermal graft. Ann Plast Surg 41: 503-507, 1998.

31. Shulman J: Clinical evaluation of an acellular dermal allograft for increasing the zone of attached gingiva. Pract Periodontics Aesthet Dent 8: 201-208, 1996.

32. Thoma DS, Benic GI, Zwahlen M, Hammerle CH and Jung RE: A systematic review assessing soft tissue augmentation techniques. Clin Oral Implants Res 20 (Suppl 4): 146-165, 2009.

33. Webster K: Early results using a porcine dermal collagen implant as an interpositional barrier to prevent recurrent Frey's syndrome. Br J Oral Maxillofac Surg 35: 104-106, 1997.

34. Govindaraj S, Cohen M, Genden EM, Costantino PD and Urken ML: The use of acellular dermis in the prevention of Frey's syndrome. Laryngoscope 111: 1993-1998, 2001.

35. Li DZ, Wu YH, Wang XL, Liu SY and Li ZJ: [Prospective cohort study on prevention of Frey syndrome in parotid surgery]. Zhonghua Wai Ke Za Zhi 44: 1033-1035, 2006.

36. Sinha UK, Saadat D, Doherty CM and Rice DH: Use of AlloDerm implant to prevent Frey syndrome after parotidectomy. Arch Facial Plast Surg 5: 109-112, 2003

37. Ye WM, Zhu HG, Zheng JW, et al: Use of allogenic acellular dermal matrix in prevention of Frey's syndrome after parotidectomy. Br J Oral Maxillofac Surg 46: 649-652, 2008.

38. Yu K, Yang J, Li MJ and Ma HB: [Clinical application of acellular dermal matrix to prevent gustatory sweating syndrome]. Zhonghua Kou Qiang Yi Xue Za Zhi 42: 570-571, 2007.

39. Chen W, Li J, Yang Z, Yongjie W, Zhiquan W and Wang Y: SMAS fold flap and ADM repair of the parotid bed following removal of parotid haemangiomas via pre- and retroauricular incisions to improve cosmetic outcome and prevent Frey's syndrome. J Plast Reconstr Aesthet Surg 61: 894-900, 2008.
40. Clayman MA and Clayman LZ: Use of AlloDerm as a barrier to treat chronic Frey's syndrome. Otolaryngol Head Neck Surg 124: 687, 2001.

41. Papadogeorgakis N, Petsinis V, Christopoulos P Mavrovouniotis N and Alexandridis C: Use of a porcine dermal collagen graft (Permacol) in parotid surgery. Br J Oral Maxillofac Surg 47: 378-381, 2009.

42. Higgins JPT and Green S (eds.): Cochrane Handbook for Systematic Reviews of Interventions version 5.1.0 (updated March 2011). The Cochrane Collaboration, 2011. Available from www.cochrane-handbook.org.

43. Jadad AR, Moore RA, Carroll D, et al: Assessing the quality of reports of randomized clinical trials: is blinding necessary? Control Clin Trials 17: 1-12, 1996.

44. Higgins JP and Thompson SG: Quantifying heterogeneity in a meta-analysis. Stat Med 21: 1539-1558, 2002.

45. Egger M and Smith GD: Bias in location and selection of studies. BMJ 316: 61-66, 1998

46. MacKinnon $\mathrm{C}$ and Lovie M: An alternative treatment for Frey syndrome. Plast Reconstr Surg 103: 745-746, 1999

47. Curry JM, King N, Reiter D, Fisher K, Heffelfinger RN and Pribitkin EA: Meta-analysis of surgical techniques for preventing parotidectomy sequelae. Arch Facial Plast Surg 11: 327-331, 2009.

48. Sachsman SM and Rice DH: Use of AlloDerm implant to improve cosmesis after parotidectomy. Ear Nose Throat J 86 512-513, 2007.

49. Lopez Gutierrez JC: The SMAS fold flap and ADM repair of the parotid bed following removal of parotid haemangiomas via pre- and retroauricular incisions to improve cosmetic outcome and prevent Frey's syndrome. J Plast Reconstr Aesthet Surg 61: 900, 2008.

50. Wu JK: The SMAS fold flap and ADM repair of the parotid bed following removal of parotid haemangiomas via pre- and retroauricular incisions to improve cosmetic outcome and prevent Frey's syndrome. J Plast Reconstr Aesthet Surg 21: 889-900, 2008.

51. Rustemeyer J, Eufinger $\mathrm{H}$ and Bremerich A: The incidence of Frey's syndrome. J Craniomaxillofac Surg 36: 34-37, 2008.

52. Malatskey S, Rabinovich I, Fradis M and Peled M: Frey syndrome - delayed clinical onset: a case report. Oral Surg Oral Med Oral Pathol Oral Radiol Endod 94: 338-340, 2002.

53. Wenzel GI and Draf W: Unusually long latency before the appearance of Frey's syndrome after parotidectomy. HNO 52: 554-556, 2004 (In German).

54. Shuman AG and Bradford CR: Ethics of Frey syndrome: ensuring that consent is truly informed. Head Neck 32: 1125-1128, 2010.

55 Schulz KF, Altman DG, Moher D and Group C: CONSORT 2010 statement: updated guidelines for reporting parallel group randomised trials. BMJ 340: c332, 2010. 